\title{
Respiratory Muscle Function in a Large Cohort of Healthy Subjects: Can Strength Predict Endurance?
}

\author{
Olga Torre Alfredo Chetta \\ Department of Clinical Sciences, Section of Respiratory Diseases, University of Parma, Parma, Italy
}

Respiratory function depends on coordinated activity of the respiratory muscles which assure effective ventilation. Several conditions such as chronic obstructive pulmonary disease (COPD), neuromuscular diseases and congestive heart failure can impair respiratory muscle function, leading to reduced respiratory muscle strength and endurance [1]. Moreover, respiratory muscle training has been shown to significantly improve respiratory muscle strength and endurance in patients suffering from COPD [2]. Therefore, measuring respiratory muscle function may be clinically relevant in all disease states involving respiratory muscles. The maximum static inspiratory pressure $\left(\mathrm{PI}_{\max }\right)$ and the maximum static expiratory pressure $\left(\mathrm{PE}_{\max }\right)$ generated at the mouth are simple techniques to estimate inspiratory and expiratory muscle strength, respectively [3]. Inspiratory muscle endurance can be measured with different tests: the most common techniques use resistive and threshold loading devices. Whereas normal values for $\mathrm{PI}_{\max }$ and $\mathrm{PE}_{\max }$ have been reported in adults as well as in children and elderly [4, 5], normal values for inspiratory muscle endurance have not yet been developed. In the early 1980s, Nickerson and Knees [6] measured endurance as sustainable inspiratory pressure, using a threshold loading device, but the study involved a small number of patients with a wide age range.

Although strength and endurance appear to be closely linked in many conditions, there are several circumstances such as COPD, asthma, and heart failure in which endurance cannot be accurately predicted from measurements of maximum respiratory pressures [3]. Thus, endurance measurement can be helpful to evaluate the respiratory muscle involvement in normal and pathological conditions in addition to measurement of muscle strength. The study by Reiter et al. [7], published in this issue of Respiration, is the first to evaluate inspiratory muscle endurance $\left(\mathrm{Tl}_{\mathrm{im}}\right)$ using a flow-dependent resistive loading device in a large population of 68 healthy Austrian individuals with an age range from 17 to 75 years. The authors divided the subjects into five age groups, and investigated $\mathrm{Tl}_{\mathrm{im}}$ and its relation to anthropometric, spirometric data and $\mathrm{PI}_{\max }$. They found a high interindividual but low intraindividual variability for both $\mathrm{Tl}_{\mathrm{im}}$ and $\mathrm{PI}_{\max }$.

In accordance with previous studies, $\mathrm{PI}_{\max }$ was negatively related to age and positively related to weight and spirometric parameters. Interestingly, the authors found that $\mathrm{Tl}_{\mathrm{im}}$ was not related either to respiratory effort sen-

\section{KARGER \\ Fax +41613061234 E-Mail karger@karger.ch} www.karger.com
(C) 2006 S. Karger AG, Basel 0025-7931/06/0735-0581\$23.50/0

Accessible online at: www.karger.com/res
Dr. Olga Torre

Clinica Pneumologica, Azienda Ospedaliera-Università di Parma

Viale G. Rasori, 10

IT-43100 Parma (Italy)

Tel. +39 0521703 414, Fax +390521 292 615, E-Mail olga-t@libero.it 
sation, or to $\mathrm{PI}_{\max }$, spirometric and anthropometric data. Moreover, because of the great interindividual variability, they were not able to establish normal values for $\mathrm{Tl}_{\mathrm{im}}$. The findings of this study [7] indicate that $\mathrm{Tl}_{\mathrm{im}}$, evaluated with resistive loads, cannot be inferred by other physio- logic factors and has to be measured in addition to $\mathrm{PI}_{\max }$, when studying inspiratory muscle function. Further studies are necessary to assess the clinical significance of serial measurements of $\mathrm{Tl}_{\mathrm{im}}$ in the follow-up of patients with respiratory muscle impairment.

\section{References}

1 Laghi F, Tobin MJ: Disorders of the respiratory muscles. Am J Respir Crit Care Med 2003; 168:10-48.

2 Lotters F, van Tol B, Kwakkel G, Gosselink R: Effects of controlled inspiratory muscle training in patients with COPD: a meta-analysis. Eur Respir J 2002;20:570-576.

3 ATS/ERS statement on respiratory muscle testing. Am J Respir Crit Care Med 2002;166: 518-624.
4 Wilson SH, Cooke NT, Edwards RHT, Spiro SG: Predicted normal values for maximal respiratory pressures in Caucasian adults and children. Thorax 1984;39:535-538.

5 Enrigth P, Kronmal RA, Manolio TA, Schenker MB, Hyatt RE: Respiratory muscle strength in the elderly. Correlates and reference values. Am J Respir Crit Care Med 1994; 149:430438.
6 Nickerson BG, Keens TG: Measuring ventilatory muscle endurance in humans as sustainable inspiratory pressure. J Appl Physiol 1982; 52:768-772.

7 Reiter M, Totzauer A, Werner I, Koessler W, Zwick H, Wanke T: Evaluation of inspiratory muscle function in a healthy Austrian population - practical aspects. Respiration 2006; 73:590-596. 